\title{
Is Biochemical Follow Up Possible in Peripheral Arterial Disease Treatment: Hypoxia Inducible Factor-1 Alpha?
}

\author{
Cihan Yücel ${ }^{1}$, Mete Gürsoy ${ }^{1}$, Serkan Ketenciler ${ }^{1}$, Aslıhan Tenekeciğil ${ }^{2}$, Feryaz Kızıltan ${ }^{1}$, \\ and Nihan Kayalar ${ }^{1}$ \\ 'Department of Cardiovascular Surgery, Prof Dr Cemil Tascıoglu City Hospital, İstanbul, ${ }^{2}$ Medical Laboratory, Bağcılar Training and \\ Research Hospital, İstanbul, Turkey
}

Purpose: The hypoxia inducible factor (HIF)-1 is a dimeric protein complex that plays an integral role in the body's response to hypoxia. This study aimed to analyze the regulation of HIF-1 $\alpha$ following vascular and/or endovascular surgery in peripheral arterial disease (PAD) patients.

Materials and Methods: A total of 40 patients with PAD ( $\geq$ Rutherford category 3 ) were included in this prospective study. The mean age was $61.9 \pm 9.2$ years. Open surgery was performed in 16 patients, and endovascular intervention was performed in 34 patients. At preoperative (T1), postoperative day 1 (T2), and month 3 (T3), the serum HIF-1 $\alpha$ levels were checked using the ELISA technique.

Results: At T3, the ankle-brachial index was significantly higher than the preoperative value $(\mathrm{P}<0.001)$. Serum HIF-1 $\alpha$ levels at $\mathrm{T} 1, \mathrm{~T} 2$, and $\mathrm{T} 3$ were $2.0 \pm 1.7 \mathrm{ng} /$ $\mathrm{mL}, 1.9 \pm 1.7 \mathrm{ng} / \mathrm{mL}$, and $1.6 \pm 1.4 \mathrm{ng} / \mathrm{mL}$, respectively. Serum HIF-1 $\alpha$ levels between $\mathrm{T} 1$ and $\mathrm{T} 3$ and between $\mathrm{T} 2$ and $\mathrm{T} 3$ were significantly different $(\mathrm{P}<0.05)$. The preoperative HIF-1 $\alpha$ levels were lowest in iliac lesions compared to femoropopliteal or tibial lesions.

Conclusion: The HIF-1 $\alpha$ levels were decreased in all patients on postoperative days, T2 and T3, compared with the preoperative values. Our results indicated that HIF-1 $\alpha$ may be a surrogate marker after revascularization in patients with PAD. Further studies are needed to analyze the sensitivity, specificity, and cut-off values of HIF- $1 \alpha$ in patients with PAD.

Key Words: Hypoxia inducible factor $1 \alpha$, Atherosclerosis, Peripheral arterial disease, Endovascular procedures, Reperfusion
Received February 4, 2021

Revised June 30, 2021

Accepted July 17, 2021

Published on August 25, 2021

\section{Corresponding author: Cihan Yücel}

Department of Cardiovascular Surgery, Prof Dr Cemil Tascioglu City Hospital, Okmeydanı Eğitim ve Araştırma Hastanesi, Darülaceze Caddesi No: 25, 34384, İstanbul 34200, Turkey

Tel: 90-212-314-5555

Fax: 90-506-418-9108

E-mail: cihanyucell@hotmail.com https://orcid.org/0000-0002-1941-0873

This article was accepted and presented at 33th European Society of Vascular Surgery Congress in Hamburg, Germany, on 24-27 September 2019 as an oral presentation.

This is an Open Access article distributed under the terms of the Creative Commons Attribution Non-Commercial License (http://creativecommons.org/licenses/by-nc/4.0) which permits unrestricted non-commercial use, distribution, and reproduction in any medium, provided the original work is properly cited.

Cite this article; Vasc Specialist Int 2021. https://doi.org/10.5758/vsi.210011

\section{INTRODUCTION}

The hypoxia inducible factor (HIF)-1 is a dimeric protein consisting of HIF- $1 \alpha$ and HIF-1 $\beta$ subunits [1,2]. It is one of the most potent transcription factors and functions as a master regulator of oxygen homeostasis, playing essential roles in cellular and systemic oxygen-dependent processes $[3,4]$. Under hypoxic conditions, the degradation of the HIF-1 $\alpha$ subunit is inhibited, and its half-life and transcriptional activity are increased [5]. The HIF pathway triggers the transcription of more than 60 target genes of proangiogenic growth factors, including the vascular endothelial 
growth factor A, angiopoietin-1 and -2, placental growth factor, and platelet derived growth factor $B[5,6]$. A recent study showed that $\mathrm{HIF}-1 \alpha$ represses thrombospondin- 2 expression, which is a potent inhibitor of angiogenesis [7].

The relationship between peripheral arterial disease (PAD) and HIF-1 has been previously reported [8]. However, to the best of our knowledge, no study has compared the preoperative and postoperative HIF-1 levels after open and/ or endovascular revascularization in patients with advanced PAD. In this prospective observational study, we aimed to investigate the value of $\mathrm{HIF}-1$ in the prognosis of patients with PAD who underwent an open or endovascular intervention.

\section{MATERIALS AND METHODS}

This prospective observational study was designed according to the STROBE statement (Strengthening the Reporting of Observational Studies in Epidemiology) [9]. Approval from the institutional ethics committee of Prof Dr Cemil Tascioglu City Hospital (Ethics committee approval number: 48670771-514.10/915) and signed informed consent were obtained. A total of 40 consecutive patients (37 males, 3 females) admitted to our institution with a diagnosis of advanced PAD ( $\geq$ Rutherford category 3 ) presenting severe claudication or rest pain (25 patients, 62.5\%) or ischemic infected or uninfected ulcers (15 patients, 37.5\%) were included. The preoperative characteristics are summarized in Table 1. All participants were examined using the ankle-

Table 1. Preoperative pateint demographics

\begin{tabular}{lc}
\hline \multicolumn{1}{c}{ Variable } & Number \\
\hline Age $(y)$ & $61.9 \pm 9.2($ range, $43-75)$ \\
Sex, male & $37(92.5)$ \\
Hypertension & $14(35.0)$ \\
Smoking & $33(82.5)$ \\
Diabetes mellitus & $19(47.5)$ \\
Coronary artery disease & $11(27.5)$ \\
Hyperlipidemia & $10(25.0)$ \\
Rutherford category & $3.4 \pm 0.6$ \\
3 & $22(55.0)$ \\
4 & $3(7.5)$ \\
5 & $15(37.5)$ \\
Preoperative ankle-brachial index & $0.39 \pm 0.2$ \\
WIfl score & \\
0 & $3(7.5)$ \\
1 & $12(30.0)$ \\
2 & $3(7.5)$ \\
\hline
\end{tabular}

Values are presented as mean \pm standard deviation or number (\%). WIfI, Wound, Ischemia, foot Infection. brachial index (ABI), Doppler ultrasonography (DUS), while 38 patients underwent computed tomography angiography (CTA) for preprocedural planning. $\mathrm{ABl}$ was measured in the usual manual fashion on admission and was repeated postoperatively $(\mathrm{ABl}=$ ankle systolic pressure/brachial systolic pressure). DUS was used for initial diagnosis to avoid excessive CTA. Carbon dioxide angiography was performed in two patients with non-dialysis-dependent chronic renal insufficiency. Open surgery was performed in 16 patients, and endovascular intervention was performed in 34 patients. Meanwhile, 10 patients received hybrid therapy (Table 2).

$\mathrm{HIF}-1 \alpha$ protein levels were quantified using a HIF-1 $\alpha$ ELISA Kit (YL Biont, Shanghai, China). The kit is a sandwich enzyme immunoassay for the in vitro quantitative measurement of this index in serum, plasma, tissue homogenates, cell lysates, cell culture supernatants, and other biological fluids. This kit was used to analyze serum samples from patients, obtained by venous puncture in the surgical suite. Control analyses were performed in service on postoperative 1 day and 3 months using the same technique. The procedure was performed according to the manufacturer's protocol. Absorbance was measured at $450 \mathrm{~nm}$. The HIF-1 $\alpha$ protein concentration in each well was calculated using the HIF-1 $\alpha$ standard equation.

Statistical analyses were performed using the SPSS Statistics version 21.0 (IBM Corp., Armonk, NY, USA). A total of 39 patients were included in the statistical analyses. The numerical variables were analyzed using visual (histograms, probability plots) and analytical (Shapiro-Wilk test) methods to determine whether they were normally distributed. Descriptive analyses of numerical variables are presented using mean, standard deviation, median, minimum, maximum, and interquartile range, while categorical variables are summarized by frequency and percentage. The Wilcoxon and Friedman tests were used for the analysis of the preoperative and postoperative data due to the violated parametric test assumptions. Bonferroni correction was used to adjust for multiple comparisons in the post hoc analysis. While investigating the associations between the

Table 2. Anatomic location of treated arteries

\begin{tabular}{lccc}
\hline \multicolumn{1}{c}{ Lesion location } & $\begin{array}{c}\text { Open } \\
\text { surgery }\end{array}$ & $\begin{array}{c}\text { Hybrid } \\
\text { treatment }\end{array}$ & $\begin{array}{c}\text { Endovascular } \\
\text { treatment }\end{array}$ \\
\hline Femoropopliteal & 16 & - & 3 \\
Iliac and femoropopliteal & - & 8 & - \\
Femoropopliteal and tibial & - & 2 & - \\
Iliac & - & - & 3 \\
Tibial & - & - & 17 \\
\hline
\end{tabular}

-, not applicable. 
variables, the correlation coefficients and their significance were calculated using the Spearman test. Statistical significance was set at $\mathrm{P}<0.05$.

\section{RESULTS}

\section{1) Patient demographics}

The mean age was $61.9 \pm 9.2$ years. The mean preoperative $A B l$ was $0.39 \pm 0.2$. The mean preoperative Rutherford category was $3.4 \pm 0.6$. The procedural success rate was $100 \%$. All patients were discharged uneventfully after a mean hospital stay of $3.3 \pm 1.5$ days. Three of the 40 patients were lost to follow-up.

\section{2) Perioperative clinical improvement}

Functional recovery was analyzed using the $\mathrm{ABl}$ and Rutherford categories. The Rutherford category at postoperative month 3 was significantly improved compared to the preoperative category $(0.70 \pm 0.84$ vs. $3.35 \pm 0.63$, $\mathrm{P}<0.001)$. Similarly, the $\mathrm{ABl}$ was significantly increased at postoperative month $3(0.39 \pm 0.20$ vs. $0.88 \pm 0.19, \mathrm{P}<0.001$; Fig. 1). No postoperative acute kidney injury was observed in any patient, including those with preoperative renal dysfunction.

\section{3) Perioperative changes of serum HIF- $1 \alpha$ level}

Serum HIF-1 $\alpha$ level at postoperative month 3 (T3, $1.63 \pm 1.37 \mathrm{ng} / \mathrm{mL})$ were significantly lower $(\mathrm{P}<0.05)$ than the preoperative $(\mathrm{T} 1,2.04 \pm 1.69 \mathrm{ng} / \mathrm{mL})$ or at postoperative day 1 levels (T2, 1.94 $\pm 1.66 \mathrm{ng} / \mathrm{mL}$; Fig. 2). The levels at T1 and $\mathrm{T} 2$ were similar $(\mathrm{P}=0.068)$. The preoperative $\mathrm{HIF}-1 \alpha$ and delta HIF-1 $\alpha$ values (T3-T1, T3-T2, T2-T1) were not associated with age, sex, Rutherford category, $\mathrm{ABl}$, smoking,

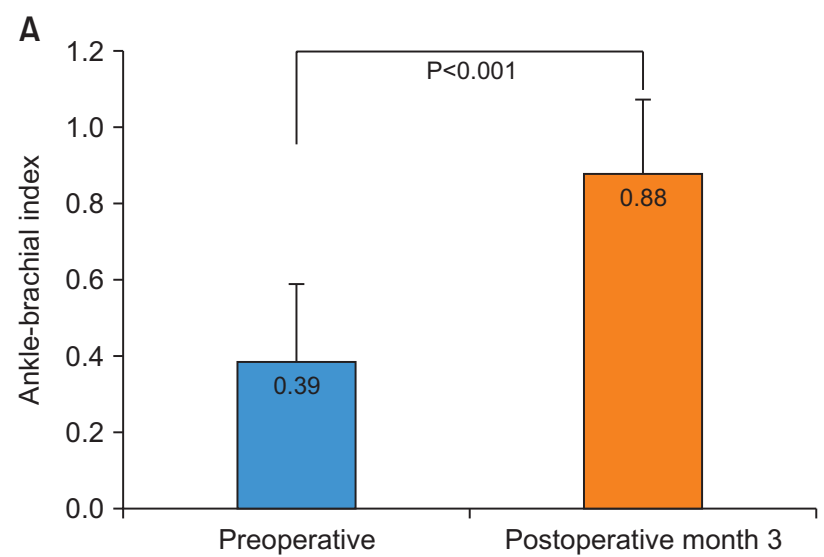

hyperlipidemia, coronary artery disease, homocysteine, and location of occluded arteries. Fig. 3 shows the perioperative distribution of the HIF-1 $\alpha$ levels.

The perioperative HIF-1 $\alpha$ levels according to the Rutherford class and occluded arteries are shown in Fig. 4. The preoperative $\mathrm{HIF}-1 \alpha$ levels did not correlate with the severity of the Rutherford category. Preoperative HIF-1 $\alpha$ levels were lowest in iliac lesions compared to femoropopliteal or tibial lesions, probably due to the compensatory collateral developments in the iliac lesions. According to the preoperative Rutherford category, the HIF-1 $\alpha$ levels decreased between T1 and T3 without statistical significance ( $P>0.05)$ : 19.7\% decrease in Category 3, 23.7\% in Category 4, and $5.2 \%$ in Category 5.

The $A B I$ significantly increased at 3 months postoperatively, proving the clinical improvement. However, preoperative and postoperative $\mathrm{HIF}-1 \alpha$ levels did not correlate with $\mathrm{ABI}(\mathrm{P}>0.05)$. Clinical improvement was assessed using the Rutherford category and the $\mathrm{ABl}$. The Rutherford category significantly improved from the preoperative mean of

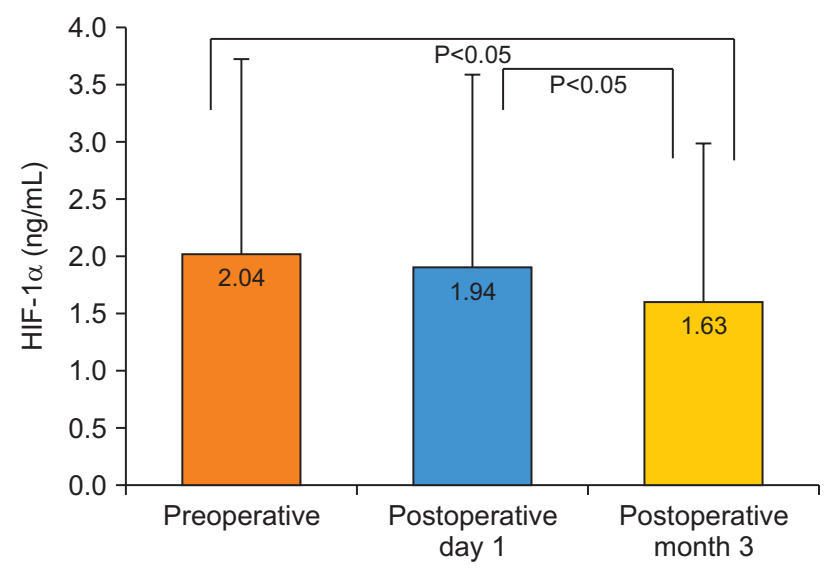

Fig. 2. Perioperative changes of the serum HIF-1 $\alpha$ levels.

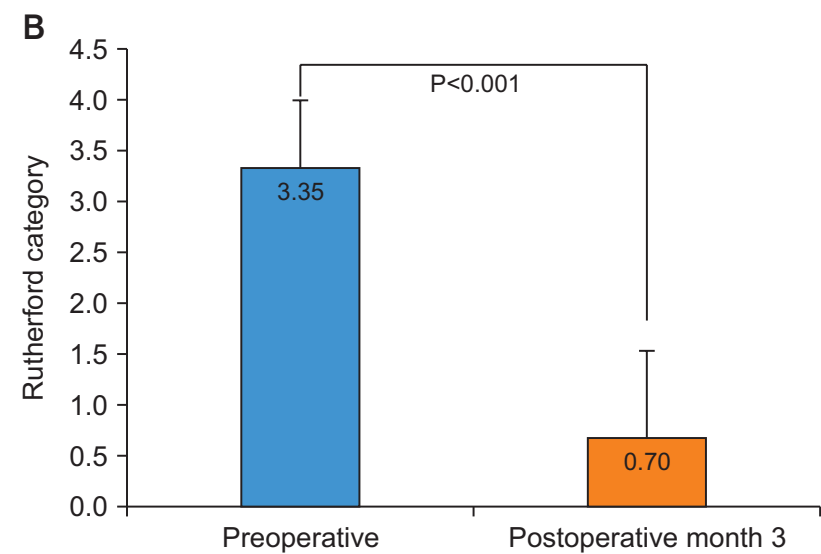

Fig. 1. The changes in the ankle-brachial index (A) and Rutherford category (B) on follow-up. 
$3.4 \pm 0.6$ to the postoperative mean of $0.7 \pm 0.8$. The $A B I$ also dramatically improved early after the operation $(0.39 \pm 0.20$ vs. $0.88 \pm 0.19 ; \mathrm{P}<0.001)$. The postoperative $\mathrm{ABl}$ and Rutherford categories were found to be inversely correlated $(r=$

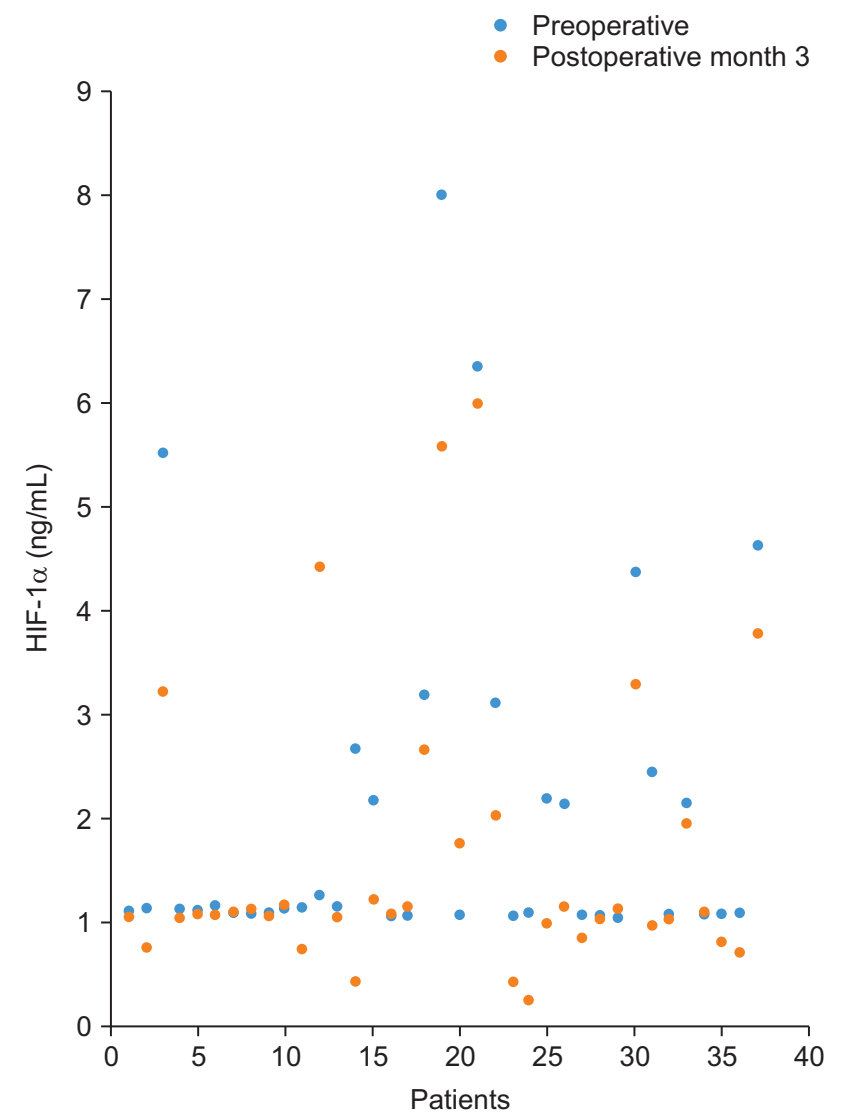

Fig. 3. Perioperative HIF-1 $\alpha$ distribution graphic.

A

Preoperative

Postoperative month 3

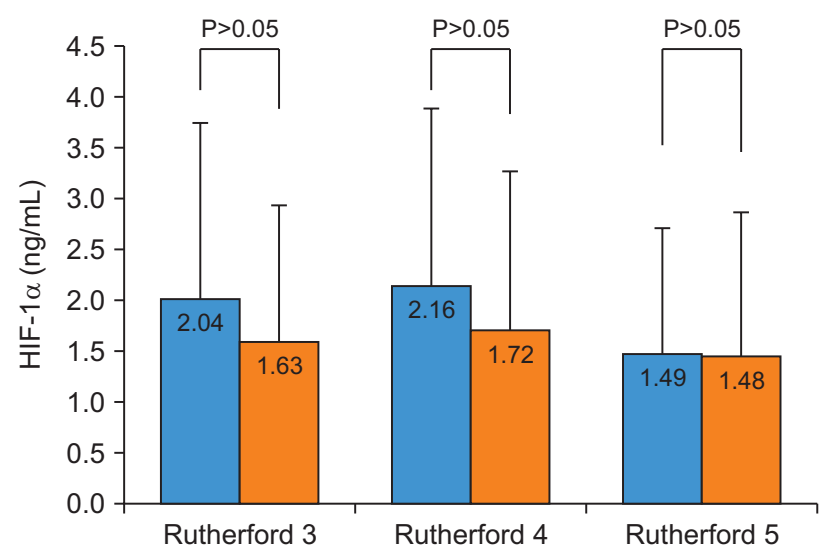

$-0.871, P<0.001)$. Meanwhile, the correlation between the preoperative $\mathrm{ABl}$ and Rutherford category was insignificant $(r=-0.310, P=0.062)$.

\section{DISCUSSION}

PAD is one of the leading causes of morbidity and mortality, with an incidence ranging between 530 and 2,380 per 100,000 person-years in Western countries [10]. In the last two decades, improved surgical and endovascular techniques have significantly decreased the amputation rates and morbidities associated with PAD [11]. Physical examination, $\mathrm{ABl}$, scoring systems, and DUS are still the most widely used follow-up instruments after peripheral vascular interventions. To the best of our knowledge, there are no reports of specific biochemical surrogate markers correlated with ischemia and revascularization that have been used for follow-up monitoring or surveillance after bypass or intervention. In the present study, we aimed to investigate the value of HIF-1 $\alpha$ as a follow-up parameter in patients with PAD after undergoing an intervention.

HIF-1 is a heterodimeric transcription factor that includes an unstable 02-regulated $\alpha$ subunit and a stable $\beta$ subunit. Under hypoxic conditions, the HIF-1 $\alpha$ subunit becomes stable, dramatically increasing its serum levels. This protein functions as an essential regulator of oxygen homeostasis and metabolism through its effects on multiple pathways regulating angiogenesis (such as those for the vascular endothelial growth factor, angiopoietins, and endothelial nitric oxide synthase). These well-documented functions of HIF-1 $\alpha$ have been observed in various experimental studies analyzing this novel potential therapeutic
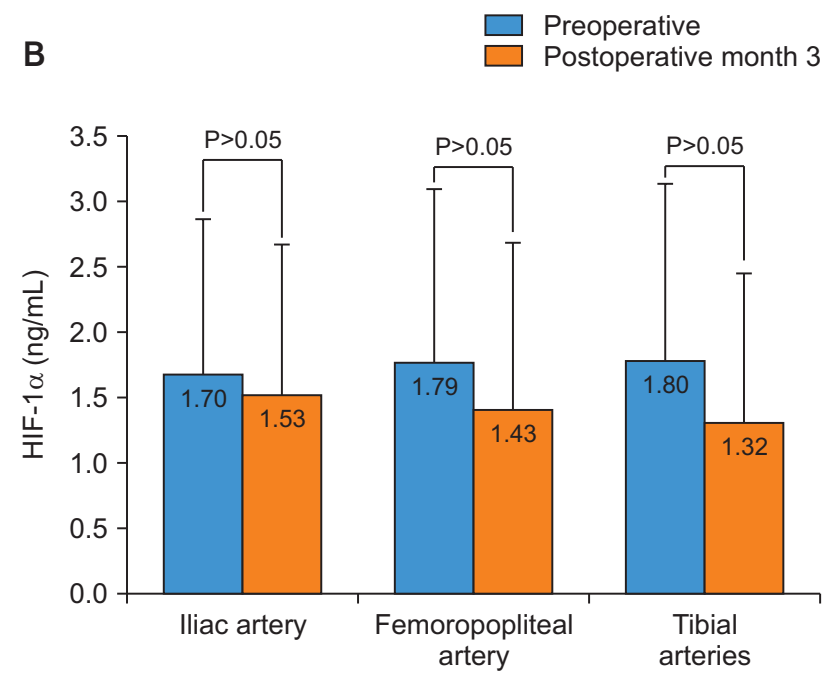

Fig. 4. Perioperative hypoxia-inducible factor (HIF)- $1 \alpha$ values according to the Rutherford category (A) and occluded arteries (B). 
target. Qi et al. [12] showed a direct relationship between $\mathrm{HIF}-1 \alpha$ and angiotensin $11-i n d u c e d$ vascular remodeling, which may affect the prognosis of remodeling-related diseases. Similarly, Schultz et al. [13] reported that HIF-1 $\alpha$ promotes the proliferative responses of human vascular smooth muscle cells to fibroblast growth factor 2, platelet derived growth factor, and epidermal growth factor in pulmonary arterial hypertensive disease.

On the other hand, HIF-1 plays a significant role in the proliferation and migration of smooth muscle cells, which are two important features of atherosclerosis. The formation of foam cells (lipid-laden macrophages), also a critical step in atherosclerosis, is mediated by HIF-1 through various mechanisms, such as dysfunctional efflux pathways in macrophages. Overall, HIF-1 exerts its effect on the pathogenesis of atherosclerosis through a variety of molecular and cellular events [14]. The activation of HIF-1 $\alpha$ is also a triggering factor for neoangiogenesis in atherosclerotic plaque sites. Growing evidence has suggested that plaque neoangiogenesis is an important contributor to intraplaque hemorrhage and rupture of atherosclerotic plaques, which are associated with critical obstructive consequences [2,1519]. These data suggest a direct relationship between HIF$1 \alpha$ expression and vascular diseases.

Increasing data have promoted the analysis of the therapeutic role of $\mathrm{HIF}-1 \alpha$. Watanabe et al. [19] reported that the inhibition of glutaredoxin-1 increased HIF-1 $\alpha$ stabilization and improved limb ischemia in mice after femoral artery ligation. Similarly, Patel et al. [20] showed significantly increased collateral vessel diameter and perfusion by arteriography in femoral artery occluded animals that received an adenoviral injection encoding the active form of HIF-1 $\alpha$. Resar et al. [21] reported that variation at the HIF-1 $\alpha$ locus may be an important determinant of collateral vessel development in patients with coronary artery disease.

Endovascular surgery has provided a new perspective featuring simultaneous multilevel interventions with or without open surgery. One of the most valuable features of this new era of vascular surgery is early symptomatic recovery.

In this study, HIF-1 $\alpha$ was considered a possible marker of clinical improvement. To the best of our knowledge, there is no established normal value for HIF-1 $\alpha$ in humans. Various studies have reported different values in a broad range of disease perspectives (malignant diseases, pregnancy, hepatocellular diseases, synovitis, etc.). The early postoperative $\mathrm{HIF}-1 \alpha$ level was mildly decreased in all patients $(2.04 \pm 1.69$ to $1.94 \pm 1.66 \mathrm{ng} / \mathrm{mL}$ ) but the decrease was only significant at 3 months $(1.63 \pm 1.37 \mathrm{ng} / \mathrm{mL})$. The pre- and postoperative HIF-1 $\alpha$ levels were not significantly correlated with the functional category or $\mathrm{ABl}$. lt was inversely related to $\mathrm{ABl}$, but there was no relationship with the Rutherford category. Our results suggest that the significant difference between consecutive $\mathrm{HIF}-1 \alpha$ levels might be related to clinical improvement. The insignificant decrease in the first measurements early after the operation may have been due to the small sample size. On the other hand, as an indicator of ischemic stress, HIF- $1 \alpha$ levels may require a certain time period to decrease, which may explain the insignificant early results and significant decrease after 3 months. We did not observe any influence from the operation type on the results.

In normoxia, HIF-1 $\alpha$ is degraded by consecutive proline hydroxylation and ubiquitylation reactions [22,23]. Therefore, $\mathrm{HIF}-1 \alpha$ decrease following revascularization is predictable, as stated in our hypothesis. Periodic HIF-1 $\alpha$ measurement may be a prognostic tool for biochemical impairment of tissue perfusion and cellular hypoxia. Although the sudden occlusion of extremity arteries can be easily diagnosed, the progressive narrowing of branch arteries and impairment of distal run-off are usually overlooked, particularly in passive, immobile, diabetic, and neuropathic patients. The proven relationship between $\mathrm{HIF}-1 \alpha$ and cellular hypoxia in our study may suggest that periodic HIF-1 $\alpha$ measurement could be a useful follow-up tool for determining the success of revascularization. Medium- and long-term measurements in the same study population and comparison of those with both clinical and radiological parameters will hopefully reveal the predictive value of HIF-1 $\alpha$ levels for the early diagnosis of procedural failures or progression of disease in other arterial sites. The follow-up levels of HIF$1 \alpha$ and the clinical symptoms may therefore decrease the unnecessary imaging of the vascular tree in some patients.

One of the most important limitations of the present study was the small sample size due to financial reasons. $\mathrm{HIF}-1 \alpha$ measurement in the healthy control group was not performed. Therefore, data on the normal HIF-1 $\alpha$ level, the cutoff value of significant ischemic lesion, sensitivity, or specificity were not available. We designed an observational study to analyze the effect of revascularization on the $\mathrm{HIF}-1 \alpha$ levels. Advanced tissue oxygenation measurements could increase the strength of this study.

This study was one of the few valuable clinical studies on this topic [24-28]. To the best of our knowledge, this was the first report comparing the HIF-1 $\alpha$ levels after open and/ or endovascular revascularization. This proof-of-concept study showed a significant decrease in the serum HIF-1 $\alpha$ levels after revascularization. Future large multicenter studies are needed to prove the prognostic value of HIF-1 $\alpha$ after revascularization in patients with PAD. 


\section{CONCLUSION}

This study showed that the HIF- $1 \alpha$ levels significantly decreased following revascularization treatment. The role of this biochemical marker as a surrogate marker or prognostic factor in the treatment of PAD should be investigated in future studies.

\section{CONFLICTS OF INTEREST}

The authors have nothing to disclose.

\section{ORCID}

Cihan Yücel

https://orcid.org/0000-0002-1941-0873

Mete Gürsoy

https://orcid.org/0000-0002-7083-476X

\author{
Serkan Ketenciler \\ https://orcid.org/0000-0003-1528-6788 \\ Aslıhan Tenekeciğil \\ https://orcid.org/0000-0002-3018-9815 \\ Feryaz Kızıltan \\ https://orcid.org/0000-0003-1113-4605 \\ Nihan Kayalar \\ https://orcid.org/0000-0002-1220-7071
}

\section{AUTHOR CONTRIBUTIONS}

Concept and design: CY, MG, NK. Analysis and interpretation: CY, MG, SK. Data collection: all authors. Writing the article: all authors. Critical revision of the article: $\mathrm{CY}, \mathrm{MG}$, NK. Final approval of the article: CY, NK. Statistical analysis: CY, SK, AT, FK. Obtained funding: none. Overall responsibility: all authors.
1) Ziello JE, Jovin IS, Huang Y. HypoxiaInducible factor (HIF)-1 regulatory pathway and its potential for therapeutic intervention in malignancy and ischemia. Yale J Biol Med 2007;80:5160.

2) Gao L, Chen Q, Zhou X, Fan L. The role of hypoxia-inducible factor 1 in atherosclerosis. J Clin Pathol 2012;65:872-876.

3) Krock BL, Skuli N, Simon MC. Hypoxia-induced angiogenesis: good and evil. Genes Cancer 2011;2:1117-1133.

4) Ho TK, Abraham DJ, Black CM, Baker DM. Hypoxia-inducible factor 1 in lower limb ischemia. Vascular 2006;14:321-327.

5) Semenza GL. Vasculogenesis, angiogenesis, and arteriogenesis: mechanisms of blood vessel formation and remodeling. J Cell Biochem 2007;102:840-847.

6) Kelly BD, Hackett SF, Hirota K, Oshima Y, Cai Z, Berg-Dixon S, et al. Cell type-specific regulation of angiogenic growth factor gene expression and induction of angiogenesis in nonischemic tissue by a constitutively active form of hypoxia-inducible factor 1 . Circ Res 2003;93:1074-1081.

7) MacLauchlan SC, Calabro NE, Huang Y, Krishna M, Bancroft T, Sharma T, et al. HIF-1 $\alpha$ represses the expression of the angiogenesis inhibitor thrombospondin-2. Matrix Biol 2018;65:45-58.

8) Rey S, Semenza GL. Hypoxia-inducible factor-1-dependent mechanisms of vascularization and vascular remodelling. Cardiovasc Res 2010;86:236-242.

9) von Elm E, Altman DG, Egger M, Pocock SJ, Gøtzsche PC, Vandenbroucke JP; STROBE Initiative. The strengthening the reporting of observational studies in epidemiology (STROBE) statement: guidelines for reporting observational studies. Prev Med 2007;45:247-251.

10) Velescu A, Clara A, Peñafiel J, Grau M, Degano IR, Martí R, et al. Peripheral arterial disease incidence and associated risk factors in a Mediterranean population-based cohort. The REGlCOR study. Eur J Vasc Endovasc Surg 2016;51:696-705.

11) Wiseman JT, Fernandes-Taylor $S$, Saha S, Havlena J, Rathouz PJ, Smith MA, et al. Endovascular versus open revascularization for peripheral arterial disease. Ann Surg 2017;265:424-430.

12) Qi D, Wei M, Jiao S, Song $Y$, Wang $X$, Xie $\mathrm{G}$, et al. Hypoxia inducible factor $1 \alpha$ in vascular smooth muscle cells promotes angiotensin ll-induced vascular remodeling via activation of CCL7-mediated macrophage recruitment. Cell Death Dis 2019;10:544.

13) Schultz K, Fanburg BL, Beasley D. Hypoxia and hypoxia-inducible factor-1alpha promote growth factorinduced proliferation of human vascular smooth muscle cells. Am J Physiol Heart Circ Physiol 2006;290:H2528H2534.

14) Jain T, Nikolopoulou EA, Xu Q, Qu A. Hypoxia inducible factor as a therapeutic target for atherosclerosis. Pharmacol Ther 2018;183:22-33.

15) Sluimer JC, Daemen MJ. Novel concepts in atherogenesis: angiogenesis and hypoxia in atherosclerosis. J Pathol 2009;218:7-29.

16) Cheng C, Chrifi I, Pasterkamp G, Duckers HJ. Biological mechanisms of microvessel formation in advanced 
atherosclerosis: the big five. Trends Cardiovasc Med 2013;23:153-164.

17) Parma L, Baganha F, Quax PHA, de Vries MR. Plaque angiogenesis and intraplaque hemorrhage in atherosclerosis. Eur J Pharmacol 2017;816:107115.

18) Chistiakov DA, Melnichenko AA, Myasoedova VA, Grechko AV, Orekhov AN. Role of lipids and intraplaque hypoxia in the formation of neovascularization in atherosclerosis. Ann Med 2017;49:661-677.

19) Watanabe $Y$, Murdoch CE, Sano S, Ido Y, Bachschmid MM, Cohen RA, et al. Glutathione adducts induced by ischemia and deletion of glutaredoxin-1 stabilize HIF-1 $\alpha$ and improve limb revascularization. Proc Natl Acad Sci U S A 2016;113:6011-6016.

20) Patel TH, Kimura H, Weiss CR, Semenza GL, Hofmann LV. Constitutively active HIF-1alpha improves perfusion and arterial remodeling in an endo- vascular model of limb ischemia. Cardiovasc Res 2005;68:144-154.

21) Resar JR, Roguin A, Voner J, Nasir K, Hennebry TA, Miller JM, et al. Hypoxia-inducible factor 1alpha polymorphism and coronary collaterals in patients with ischemic heart disease. Chest 2005;128:787-791.

22) Strowitzki MJ, Cummins EP, Taylor CT. Protein hydroxylation by hypoxiainducible factor (HIF) hydroxylases: unique or ubiquitous? Cells 2019;8:384.

23) Ferns GAA, Heikal L. Hypoxia in atherogenesis. Angiology 2017;68:472493.

24) Burki NK, Tetenta SU. Inflammatory response to acute hypoxia in humans. Pulm Pharmacol Ther 2014;27:208211.

25) Lee JD, Lai CH, Yang WK, Lee TH. Increased expression of hypoxiainducible factor- $1 \alpha$ and metallothionein in varicocele and varicose veins.
Phlebology 2012;27:409-415.

26) Asadi MR, Torkaman G, Hedayati M, Mohajeri-Tehrani MR, Ahmadi M, Gohardani RF. Angiogenic effects of low-intensity cathodal direct current on ischemic diabetic foot ulcers: a randomized controlled trial. Diabetes Res Clin Pract 2017;127:147-155.

27) Rajagopalan S, Olin J, Deitcher S, Pieczek A, Laird J, Grossman PM, et al. Use of a constitutively active hypoxia-inducible factor-1alpha transgene as a therapeutic strategy in nooption critical limb ischemia patients: phase 1 dose-escalation experience. Circulation 2007;115:1234-1243.

28) Mounier R, Pialoux V, Schmitt L, Richalet JP, Robach P, Coudert J, et al. Effects of acute hypoxia tests on blood markers in high-level endurance athletes. Eur J Appl Physiol 2009;106:713-720. 